\title{
Whole grain intake and its association with intakes of other foods, nutrients and markers of health in the National Diet and Nutrition Survey rolling programme 2008-11
}

\author{
Kay D. Mann ${ }^{1,2}$, Mark S. Pearce ${ }^{1}$, Brigid McKevith ${ }^{3}$, Frank Thielecke ${ }^{4,5}$ and Chris J. Seal ${ }^{2 *}$ \\ ${ }^{1}$ Institute of Health and Society, Newcastle University, Newcastle upon Tyne NE1 4LP, UK \\ ${ }^{2}$ Human Nutrition Research Centre, School of Agriculture, Food and Rural Development, Agriculture Building, \\ Kings Road, Newcastle University, Newcastle upon Tyne NE1 7RU, UK \\ ${ }^{3}$ Cereal Partners UK, Welwyn Garden City AL7 1RR, UK \\ ${ }^{4}$ Cereal Partners Worldwide, Lausanne, Switzerland \\ ${ }^{5}$ Nestlé Research Center, Vers chez les Blanc, Lausanne, Switzerland
}

(Submitted 13 October 2014 - Final revision received 13 January 2015-Accepted 2 February 2015)

\section{Abstract}

Epidemiological evidence suggests an inverse association between whole grain consumption and the risk of non-communicable diseases, such as CVD, type 2 diabetes, obesity and some cancers. A recent analysis of the National Diet and Nutrition Survey rolling programme (NDNS-RP) has shown lower intake of whole grain in the UK. It is important to understand whether the health benefits associated with whole grain intake are present at low levels of consumption. The present study aimed to investigate the association of whole grain intake with intakes of other foods, nutrients and markers of health (anthropometric and blood measures) in the NDNS-RP 2008-11, a representative dietary survey of UK households. A 4-d diet diary was completed by 3073 individuals. Anthropometric measures, blood pressure levels, and blood and urine samples were collected after diary completion. Individual whole grain intake was calculated with consumers categorised into tertiles of intake. Higher intake of whole grain was associated with significantly decreased leucocyte counts. Significantly higher concentrations of C-reactive protein were seen in adults in the lowest tertile of whole grain intake. No associations with the remaining health markers were seen, after adjustments for sex and age. Over $70 \%$ of this population did not consume the minimum recommend intake associated with disease risk reduction, which may explain small variation across health markers. Nutrient intakes in consumers compared with non-consumers were closer to dietary reference values, such as higher intakes of fibre, Mg and $\mathrm{Fe}$, and lower intakes of $\mathrm{Na}$, suggesting that higher intake of whole grain is associated with improved diet quality.

Key words: Whole grain intake: Whole grain associations: UK population: UK diet

Whole grains and foods containing whole grains, such as whole-grain breads, porridge and ready-to-eat cereals, are considered to be beneficial to health. Epidemiological evidence suggests an inverse linear association between whole grain consumption and the risk of many non-communicable diseases, such as CVD, type 2 diabetes (T2D), obesity and some cancers $^{(1,2)}$. Observational studies have shown that those consuming 2-3 servings of whole grains per $d$ (the upper level in most studies) have around a $21 \%$ reduction in the risk of CVD and around a $26 \%$ reduction in the risk of $\mathrm{T} 2 \mathrm{D}$ compared with never or rare consumers ${ }^{(1,3)}$. However, intervention studies have shown no such reduction in the risk of CVD markers in whole grain consumers over a 4-month $\operatorname{period}^{(4)}$. Consumers of whole grain have also been shown to have a better overall diet quality, particularly for increased fibre intake ${ }^{(5)}$. Along with insoluble fibre, bioactive components found in bran and germ of whole grains, such as antioxidant micronutrients, carotenoids, minerals, polyphenols and vitamins (to name a few), are attributed to the protective effects of whole grains on health ${ }^{(6)}$.

The recommendation to increase whole grain consumption is now global; however, dietary and quantity-specific guidance across countries is variable, with no quantitative recommendation in the $\mathrm{UK}^{(3)}$. A recent analysis of the UK dietary data has shown that the average whole grain intake is low in both adults $(20 \mathrm{~g} / \mathrm{d})$ and children $(13 \mathrm{~g} / \mathrm{d})^{(7)}$, much lower than the suggested $2-3$ daily servings $(32-48 \mathrm{~g} / \mathrm{d})$ recommended by the US Department of Agriculture (USDA) in

Abbreviations: CRP, C-reactive protein; NDNS-RP, National Diet and Nutrition Survey rolling programme; T2D, type 2 diabetes.

* Corresponding author: C. J. Seal, fax +44 191208 6720, email chris.seal@ncl.ac.uk 
the 2010 Dietary Guidelines for Americans ${ }^{(8)}$, and the recommendation of $75 \mathrm{~g}$ whole grain/10 MJ from the Danish Nutrition Foundation $^{(9)}$. It is important to understand whether the health benefits associated with whole grain intake previously attributed to higher levels of intake are still present at these low levels of consumption seen in the UK.

The aim of the present study was to investigate the association of whole grain intake with intakes of other foods, nutrients and markers of health (anthropometric and blood measures) in the National Diet and Nutrition Survey rolling programme (NDNS-RP) 2008-11.

\section{Methods}

\section{Study population}

The NDNS-RP assesses the diet, nutritional intake and status of individuals aged 1.5 years and above, living in private households in the UK (England, Scotland, Wales and Northern Ireland). Between April 2008 and March 2011, 3073 randomly selected adults and children were invited to complete a 4-d food diary, interviewed and asked to provide blood and urine samples. Further details of the NDNS-RP methodology have been described elsewhere ${ }^{(10,11)}$. In brief, participants completed an estimated food diary recording all foods and drinks consumed both at home and away from home for four and, in some cases ( $n$ 53, 2\%), three consecutive days. Participants also completed a computer-assisted personal interview, collecting information on dietary habits and lifestyle, and had height and weight measured. In a follow-up nurse visit to the household, waist:hip ratio and blood pressure were measured, and fasting blood samples were taken for those aged 4 years and above.

Food diaries for those aged 11 years and younger were completed by a parent/carer with help from the child. Processing of the food diary data was done by trained coders and editors. Food intakes were entered into the MRC HNR's (Medical Research Council, Human Nutrition Research) dietary assessment system, Diet In Nutrients Out ${ }^{(12)}$. The food composition data used was from the Department of Health's NDNS Nutrient Databank. Data coders matched each food/drink item recorded in the diary with a food code and portion code from Diet In Nutrients Out. For composite items (e.g sandwiches) and home-made meals, their component parts were assigned individual food codes. Further details of data coding and editing are outlined in Appendix A of the NDNSRP official report ${ }^{(13)}$. Food intake groups included milk, cheese, yogurt, eggs, fats, meat, fish, fruit, vegetables, pasta, rice, bread, ready-to-eat cereals, biscuits, buns, cakes, pastries, confectioneries, savoury crisps and snacks. Average daily food and nutrient intakes were derived from the food diary data by the NDNS-RP team.

Height and weight were measured at the first participant visit using a portable stadiometer and weighing scales. BMI was calculated, and for participants whose height could not be measured, estimated height based on demispan (the distance between the mid-point of the sternal notch and the finger roots with the arm outstretched laterally) was used to calculate the $\mathrm{BMI}^{(14)}$. Waist and hip circumferences were measured during a nurse visit to the participants aged 11 years and above using a tape measure. All measurements were taken twice and a third was taken if there was a discrepancy between the first two measurements above a given value (height $\geq 0.5 \mathrm{~cm}$, weight $\geq 0.2 \mathrm{~kg}$, waist and hip circumferences $\geq 3 \mathrm{~cm}$ ). For the purpose of this analysis, the mean of the closest two measurements was used.

Blood pressure level, collected during the nurse visit to the participant, was measured in the sitting position using an automated, validated machine (Omron HEM907), after 5 min of rest. Blood pressure level was only collected for participants aged 4 years and above. The mean of the second and third blood pressure readings taken at $1 \mathrm{~min}$ intervals in participants who had not eaten, drunk alcohol, exercised or smoked in the preceding $30 \mathrm{~min}$ was used. Individuals who did not have three valid blood pressure readings were excluded from the analysis.

Overnight fasting blood samples were obtained from those aged 4 years and above and from non-diabetics, otherwise non-fasting samples were obtained. However, for the purpose of this analysis, only blood analytes from participants aged 11 years and above have been investigated due to small numbers (19\%) of participants aged $1.5-10$ years providing blood samples. We included data from 13/37 adults with diabetes who provided non-fasting samples and for whom analyte data were available. Blood samples were analysed for a range of analytes ${ }^{(10)}$, including $\mathrm{Hb}$, serum total cholesterol, HDL-cholesterol, LDL-cholesterol, C-reactive protein (CRP), TAG, plasma creatinine and leucocyte counts.

The NDNS-RP was conducted according to the guidelines laid down in the Declaration of Helsinki, and ethical approval for all procedures was granted by Local Research Ethics Committees covering all areas covered in the survey. All participants gave informed consent.

\section{Estimation of whole grain intake}

As has been described previously ${ }^{(7)}$, food diary data were investigated for foods containing any whole-grain ingredient ( $n$ 221), using the HEALTHGRAIN definition of whole grain $^{(15)}$ and classification of whole-grain ingredients outlined in the study by Seal and colleagues ${ }^{(16)}$. Whole-grain content of each food identified was calculated per $100 \mathrm{~g}$, on a DM as consumed basis, and absolute daily whole grain intake in grams was calculated for consumers along with tertiles of intake. A non-consumer of whole grain was defined as an individual who did not consume any foods containing any amount of whole-grain ingredient.

\section{Weighting the data}

Data used in the analysis were weighted in order to exclude any potential selection bias in the observed results arising from non-response bias in the NDNS-RP. Weighting variables to account for any potential bias in households, main food provider, individual selection, seasonality and for age, sex and regional profiles of participating individuals was provided 
by the NDNS team. Weighting for non-response to nurse visit and providing a blood sample were also used in the respective analyses. Full details of weight computation are described in Appendix $\mathrm{B}$ of the NDNS national report ${ }^{(17)}$

\section{Statistical analysis}

Means and standard deviations of food and nutrient intakes were calculated for non-consumers of whole grain and by tertile of intake for consumers. Means and standard deviations of health marker measures were also calculated for non-consumers of whole grain and by tertile of intake for consumers. Associations across whole grain intakes (non-consumers and tertile groups) and intakes of other foods, nutrients and health markers were investigated using linear regression with values adjusted for sex and age in multivariable models; the dependent variable was the outcome of interest (e.g. fibre intake) and the independent predictor was intake group (non-consumer, tertile 1, tertile 2 and tertile 3 ). To eliminate potential confounding by sex and age, any significant associations were then adjusted for sex and, if the association remained significant, further adjusted for age. Differences between non-consumers and tertiles of whole grain intake were assessed using independent $t$ tests, adjusting for sex, within the regression modelling. $P<0.05$ was used to denote significance throughout all statistical analysis.

All statistical analysis was performed in Stata version 12 (StataCorp) utilising the complex survey functions.

\section{Results}

In this population of 1052 children/teenagers ( $1 \cdot 5-17$ years) and 1521 adults (18+ years), 15\% of children/teenagers and $18 \%$ of adults did not consume any whole grain (Table 1 ). The mean whole grain intake ranged from $5.4(\mathrm{SD} 2 \cdot 8) \mathrm{g} / \mathrm{d}$ in tertile 1 to $40 \cdot 1(\mathrm{sD} 16 \cdot 4) \mathrm{g} / \mathrm{d}$ in tertile 3 for children/teenagers and from $8.4(\mathrm{SD} 4.6) \mathrm{g} / \mathrm{d}$ in tertile 1 to $61(\mathrm{SD} 26.8) \mathrm{g} / \mathrm{d}$ in tertile 3 for adults. The mean whole grain intake of consumers included only in tertile 3 (29\% of children/teenagers, $28 \%$ of adults and $29 \%$ of the total population) achieved the minimum recommendation $(32 \mathrm{~g} / \mathrm{d})$ for reduced risk of noncommunicable disease. The percentages of males and females across non-consumers and tertile groups were similar in children/teenagers and adults, although there was a higher proportion of child/teenage males in tertile 3 (Table 1). Mean age was lower across non-consumers and tertile groups in children/teenagers and was greater across adult non-consumers and tertile groups. Age differences in whole grain intake have been reported elsewhere ${ }^{(7)}$.

\section{Intakes of nutrients}

Whole grain consumers had significantly different intakes of some nutrients than non-consumers (Table 2). Nutrient intakes reported here come exclusively from foods consumed over the diet diary and do not include vitamin or mineral supplements. Significant associations for higher intakes of whole grain were seen with greater intake of total energy and energy from protein, carbohydrates and total sugar (in children/teenagers only). Higher intake of whole grain was also significantly associated with greater intake of fibre, Fe, Ca, vitamin $\mathrm{E}$ (in adults only), $\mathrm{K}, \mathrm{P}, \mathrm{Mg}$, thiamin, riboflavin, niacin (in children/teenagers only), vitamin B12 (in adults only) and vitamin D (in adults only). Higher intake of whole grain was significantly associated with lower intake of energy from non-milk extrinsic sugar, fat and alcohol (in adults only).

Compared with non-consumers of whole-grain foods, consumers in tertile 3 had significantly higher intakes of total energy, energy from protein (in adults only), carbohydrates and total sugar (in children/teenagers only) and significantly higher intakes of fibre, $\mathrm{Fe}, \mathrm{Ca}$, vitamin $\mathrm{E}$ (in adults only), $\mathrm{K}, \mathrm{P}, \mathrm{Mg}$, thiamin, riboflavin, niacin (in children/teenagers only), vitamin B12 (in adults only) and vitamin D (in adults only) (Table 2). Consumers in tertile 3 also had significantly lower intakes of energy from non-milk extrinsic sugar (in adults only), fat (in children/teenagers only) and alcohol (in adults only), and significantly lower intakes of $\mathrm{Na}$ compared with non-consumers of whole-grain foods.

Table 1. Whole grain intake in children/teenagers and in adults

(Mean values and standard deviations, and numbers and percentages of participants)

\begin{tabular}{|c|c|c|c|c|c|c|c|c|c|c|}
\hline & \multicolumn{10}{|c|}{ Whole grain intake $(\mathrm{g} / \mathrm{d})$} \\
\hline & \multicolumn{2}{|c|}{ Non-consumers } & \multicolumn{2}{|c|}{ T1 (lowest) } & \multicolumn{2}{|c|}{ T2 } & \multicolumn{2}{|c|}{ T3 (highest) } & \multicolumn{2}{|c|}{ Total population } \\
\hline & Mean & SD & Mean & SD & Mean & SD & Mean & SD & Mean & SD \\
\hline Children/teenagers ( $1.5-17$ years) & 0 & & $5 \cdot 4$ & $2 \cdot 8$ & $16 \cdot 5$ & 3.7 & $40 \cdot 1$ & $16 \cdot 4$ & $17 \cdot 8$ & $18 \cdot 1$ \\
\hline Sex $(\%$ male $)$ & \multicolumn{2}{|c|}{50} & \multicolumn{2}{|c|}{44} & \multicolumn{2}{|c|}{49} & \multicolumn{2}{|c|}{60} & \multicolumn{2}{|c|}{51} \\
\hline Age (years) & $10 \cdot 7$ & $5 \cdot 2$ & $9 \cdot 6$ & 4.9 & $9 \cdot 1$ & 4.7 & 8.9 & 4.7 & 9.4 & 4.9 \\
\hline Unweighted & & & & & & & & & & \\
\hline$n$ & \multicolumn{2}{|c|}{227} & \multirow{2}{*}{\multicolumn{2}{|c|}{415}} & \multirow{2}{*}{\multicolumn{2}{|c|}{418}} & \multicolumn{2}{|c|}{442} & \multicolumn{2}{|c|}{1502} \\
\hline$\%$ & \multicolumn{2}{|c|}{15} & & & & & \multicolumn{2}{|c|}{29} & \multicolumn{2}{|c|}{100} \\
\hline Adults (18+ years) & 0 & & $8 \cdot 4$ & $4 \cdot 6$ & $25 \cdot 7$ & $5 \cdot 5$ & $61 \cdot 0$ & $26 \cdot 8$ & $26 \cdot 2$ & $27 \cdot 8$ \\
\hline Sex $(\%$ male $)$ & \multicolumn{2}{|c|}{56} & \multicolumn{2}{|c|}{44} & \multicolumn{2}{|c|}{43} & \multicolumn{2}{|c|}{55} & \multicolumn{2}{|c|}{49} \\
\hline Age (years) & $40 \cdot 6$ & $17 \cdot 7$ & $44 \cdot 1$ & $19 \cdot 1$ & $49 \cdot 6$ & 18.9 & $49 \cdot 4$ & $17 \cdot 7$ & $46 \cdot 4$ & $18 \cdot 8$ \\
\hline \multicolumn{11}{|l|}{ Unweighted } \\
\hline$n$ & \multicolumn{2}{|c|}{277} & \multicolumn{2}{|c|}{431} & \multicolumn{2}{|c|}{426} & \multicolumn{2}{|c|}{437} & \multicolumn{2}{|c|}{1571} \\
\hline$\%$ & \multicolumn{2}{|c|}{18} & \multicolumn{2}{|c|}{27} & \multicolumn{2}{|c|}{27} & \multicolumn{2}{|c|}{28} & & \\
\hline
\end{tabular}

$\mathrm{T}$, tertile. 
Table 2. Mean nutrient intakes of non-consumers and by tertiles $(T)$ of whole grain intake

\begin{tabular}{|c|c|c|c|c|c|c|c|c|c|c|}
\hline \multirow[b]{3}{*}{ Nutrient } & \multicolumn{4}{|c|}{ Child/teenage mean } & \multirow[b]{3}{*}{$P \dagger$} & \multicolumn{4}{|c|}{ Adult mean } & \multirow[b]{3}{*}{$P \dagger$} \\
\hline & \multicolumn{4}{|c|}{ Whole grain intake/d } & & \multicolumn{4}{|c|}{ Whole grain intake/d } & \\
\hline & $0 \mathrm{~g} / \mathrm{d}$ & T1 & $\mathrm{T} 2$ & T3 & & $0 \mathrm{~g} / \mathrm{d}$ & T1 & T2 & T3 & \\
\hline Energy (kcal) & 1549 & 1528 & 1582 & $1683^{*}$ & $<0.001$ & 1862 & 1743 & 1784 & $1987^{\star}$ & $<0.001$ \\
\hline Energy (MJ) & 6.5 & $6 \cdot 4$ & $6 \cdot 7$ & $7 \cdot 1^{\star}$ & $<0.001$ & 7.8 & $7 \cdot 3$ & 7.5 & $8 \cdot 4^{*}$ & $<0.001$ \\
\hline$\%$ energy from protein & $14 \cdot 8$ & $14 \cdot 6$ & 14.5 & $15 \cdot 1$ & $<0.05$ & $15 \cdot 8$ & $16 \cdot 2$ & $16 \cdot 9^{*}$ & $16 \cdot 7^{\star}$ & $<0.01$ \\
\hline$\%$ energy from carbohydrate & $50 \cdot 3$ & $50 \cdot 7$ & $51 \cdot 5^{\star}$ & $51 \cdot 8^{\star}$ & $<0.01$ & 44.9 & 44.5 & $45 \cdot 5$ & $46 \cdot 6^{\star}$ & $<0.001$ \\
\hline$\%$ energy from total sugar & $21 \cdot 8$ & $22 \cdot 7$ & $23 \cdot 6^{*}$ & $23 \cdot 0^{\star}$ & $<0.01$ & 19.5 & $19 \cdot 1$ & $19 \cdot 8$ & $19 \cdot 9$ & $\geq 0.05$ \\
\hline$\%$ energy from NME sugars & $14 \cdot 3$ & $14 \cdot 6$ & $14 \cdot 8$ & $13 \cdot 8$ & $<0.01$ & $13 \cdot 6$ & $12^{*}$ & $11 \cdot 2^{*}$ & $10 \cdot 6^{\star}$ & $<0.001$ \\
\hline$\%$ energy from fat & 34.7 & 34.4 & $33.8^{*}$ & $33 \cdot 0^{*}$ & $<0.001$ & 33.7 & $34 \cdot 0$ & 32.9 & $32 \cdot 8$ & $<0.05$ \\
\hline$\%$ energy from saturated fat & $13 \cdot 0$ & 13.4 & $13 \cdot 3$ & $13 \cdot 1$ & $\geq 0.05$ & $12 \cdot 4$ & $12 \cdot 7$ & $12 \cdot 2$ & $12 \cdot 2$ & $\geq 0.05$ \\
\hline$\%$ energy from alcohol & 0.2 & 0.2 & $0 \cdot 1$ & 0.1 & $\geq 0.05$ & $5 \cdot 6$ & $5 \cdot 3$ & $4 \cdot 7$ & $3 \cdot 9^{*}$ & $<0.05$ \\
\hline Fibre $(\mathrm{g} / 10 \mathrm{MJ})$ & $14 \cdot 8$ & $15 \cdot 1^{*}$ & $16 \cdot 8^{*}$ & $19 \cdot 3^{*}$ & $<0.001$ & 14.4 & $16 \cdot 2^{*}$ & $19 \cdot 2^{*}$ & $21 \cdot 6^{\star}$ & $<0.001$ \\
\hline $\mathrm{Na}(\mathrm{mg} / 10 \mathrm{MJ})$ & 3051 & 2978 & $2885^{\star}$ & $2910^{*}$ & $\geq 0.05$ & 3090 & 3027 & 2989 & $2934^{*}$ & $\geq 0.05$ \\
\hline $\mathrm{Fe}(\mathrm{mg} / 10 \mathrm{MJ})$ & 11.7 & $12 \cdot 3^{\star}$ & $13 \cdot 3^{*}$ & $15 \cdot 0^{*}$ & $<0.001$ & $12 \cdot 3$ & $13 \cdot 6^{*}$ & $14 \cdot 7^{\star}$ & $15 \cdot 2^{*}$ & $<0.001$ \\
\hline $\mathrm{Ca}(\mathrm{mg} / 10 \mathrm{MJ})$ & 1147 & 1169 & $1234^{\star}$ & $1276^{*}$ & $<0.001$ & 984 & 1044 & $1114^{*}$ & $1149^{*}$ & $<0.001$ \\
\hline Vitamin E (mg/10 MJ) & $11 \cdot 1$ & $10 \cdot 5^{\star}$ & $10 \cdot 7$ & $10 \cdot 5$ & $\geq 0.05$ & 11.0 & $11 \cdot 2$ & $11 \cdot 8$ & $12 \cdot 1^{\star}$ & $<0.001$ \\
\hline $\mathrm{K}(\mathrm{mg} / 10 \mathrm{MJ})$ & 3233 & 3255 & 3322 & $3422^{*}$ & $<0.001$ & 3303 & $3549^{*}$ & $3884^{*}$ & $3916^{*}$ & $<0.001$ \\
\hline$P(\mathrm{mg} / 10 \mathrm{MJ})$ & 1489 & 1520 & $1563^{\star}$ & $1665^{\star}$ & $<0.001$ & 1502 & 1556 & $1674^{\star}$ & $1752^{*}$ & $<0.001$ \\
\hline $\mathrm{Mg}(\mathrm{mg} / 10 \mathrm{MJ})$ & $264 \cdot 7$ & $276 \cdot 1^{*}$ & $294 \cdot 3^{*}$ & $326^{*}$ & $<0.001$ & 286 & $306^{*}$ & $344^{*}$ & $376^{\star}$ & $<0.001$ \\
\hline Thiamin (mg/10 MJ) & 1.8 & $1.9^{*}$ & $2 \cdot 0^{*}$ & $2 \cdot 1^{*}$ & $<0.001$ & 1.8 & 1.8 & $2 \cdot 0^{*}$ & $2 \cdot 0^{*}$ & $<0.001$ \\
\hline Riboflavin (mg/10 MJ) & $2 \cdot 0$ & $2 \cdot 1$ & $2 \cdot 3^{\star}$ & $2 \cdot 4^{\star}$ & $<0.001$ & 1.8 & $2 \cdot 0$ & $2 \cdot 2^{*}$ & $2 \cdot 3^{\star}$ & $<0.001$ \\
\hline Niacin (mg/10 MJ) & 41.7 & $41 \cdot 7$ & 41.4 & $44 \cdot 2^{*}$ & $<0.01$ & $47 \cdot 9$ & $46 \cdot 7$ & 48.5 & 49.1 & $\geq 0.05$ \\
\hline Vitamin B6 (mg/10 MJ) & $2 \cdot 8$ & $2 \cdot 8$ & $2 \cdot 8$ & $2 \cdot 9$ & $\geq 0.05$ & $3 \cdot 1$ & 2.9 & $3 \cdot 0$ & $3 \cdot 0$ & $\geq 0.05$ \\
\hline Vitamin B12 ( $\mu \mathrm{g} / 10 \mathrm{MJ})$ & $6 \cdot 0$ & $5 \cdot 8$ & $6 \cdot 1$ & $6 \cdot 4$ & $\geq 0.05$ & $6 \cdot 7$ & $6 \cdot 9$ & $7 \cdot 6$ & $7 \cdot 7^{\star}$ & $<0.05$ \\
\hline Vitamin $D(\mu \mathrm{g} / 10 \mathrm{MJ})$ & 3.3 & 2.9 & 3.1 & $3 \cdot 1$ & $\geq 0.05$ & 3.7 & 3.5 & 4.0 & $4 \cdot 1^{*}$ & $<0.01$ \\
\hline$n$ (unweighted) & 227 & 415 & 418 & 442 & & 277 & 431 & 426 & 437 & \\
\hline
\end{tabular}

NME, non-milk extrinsic.

*Values are significantly different from non-consumers $(P<0.05 ; t$ test, adjusted for sex).

$\dagger$ Association across intakes of whole grain and nutrient intakes (linear regression, adjusted for sex).

After adjustment for sex and age, the associations of higher intake of whole grain with greater intakes of vitamins B12 and $\mathrm{D}$ in adults only were no longer significant. Adjustment for sex and age did not attenuate any other of the associations found with nutrient intakes.

\section{Intakes of other foods}

Higher intake of whole grain was significantly associated with greater intake of milk, cheese (in children/teenagers only), yogurt, fats and spreads, fish (in adults only), fruit and vegetables, wholemeal bread, ready-to-eat cereals, biscuits and cakes (in adults only) (Table 3). Higher intake of whole grain was also significantly associated with lower intake of white meat (in children/teenagers only), red meat (in adults only), white bread and savoury crisps and snacks (in adults only).

Mean intakes of milk, cheese (in children/teenagers only), yogurt, fish (in adults only), fruit and vegetables, wholemeal bread, ready-to-eat cereals, biscuits, cakes (in adults only) and sugar confectioneries (in children/teenagers only) were significantly higher in consumers in tertile 3 compared with non-consumers (Table 3). However, mean intakes of white meat (in children/teenagers only), red meat (in adults only), white bread, and savoury crisps and snacks (in adults only) were significantly lower in consumers in tertile 3 compared with non-consumers. Adjustment for age and sex did not attenuate any of the associations found with intakes of other foods.

\section{Health markers}

Significant associations were seen from lowest to highest levels of whole grain intake with a fall in systolic blood pressure (in children/teenagers only) and a fall in leucocyte counts (Table 4). After adjustment for age, the association with systolic blood pressure in children/teenagers was no longer significant. In comparison with non-consumers of whole grain, adult consumers in tertile 1 had significantly lower CRP concentrations (tertile $1: 2.8 v .3 .8 \mathrm{mg} / \mathrm{l} ; P=0.04$ ). However, the reductions in CRP concentrations of adult consumers in tertile 2 and tertile 3 , although present, were not significantly different from non-consumers (Table 4). Child/ teenage consumers in tertile 2 and tertile 3 had significant lower systolic blood pressure than non-consumers (tertile 2: $107 \cdot 1$, tertile $3: 107 \cdot 4 v \cdot 110 \cdot 3 \mathrm{mmHg}$, tertile $2: P=0 \cdot 02$, tertile 3 : $P=0.01)$; however, this association did not remain after adjustment for age. No other significant associations or differences were seen between whole grain intake and other health markers.

\section{Discussion}

In this UK population, with low consumption of whole grain ${ }^{(7)}$, a significant decrease in leucocyte counts was seen across groups of intake, after adjustment for age and sex. In adults, CRP concentrations were significantly lower in low consumers 
Table 3. Mean intakes of other foods in non-consumers and by tertiles (T) of whole grain intake

\begin{tabular}{|c|c|c|c|c|c|c|c|c|c|c|}
\hline \multirow[b]{3}{*}{ Food $(g)$} & \multicolumn{4}{|c|}{ Child/teenage mean } & \multirow[b]{3}{*}{$P+$} & \multicolumn{4}{|c|}{ Adult mean } & \multirow[b]{3}{*}{$P+$} \\
\hline & \multicolumn{4}{|c|}{ Whole grain intake/d } & & \multicolumn{4}{|c|}{ Whole grain intake/d } & \\
\hline & $0 \mathrm{~g} / \mathrm{d}$ & $\mathrm{T} 1$ & $\mathrm{~T} 2$ & T3 & & $0 \mathrm{~g} / \mathrm{d}$ & $\mathrm{T} 1$ & $\mathrm{~T} 2$ & T3 & \\
\hline Milk & $184 \cdot 8$ & $177 \cdot 2$ & $207 \cdot 2$ & $237 \cdot 1^{\star}$ & $<0.01$ & $117 \cdot 4$ & $135 \cdot 8^{\star}$ & $170^{*}$ & $197 \cdot 6^{*}$ & $<0.001$ \\
\hline Cheese & $8 \cdot 2$ & $10 \cdot 3$ & $9 \cdot 6$ & $11 \cdot 7^{*}$ & $<0.01$ & 14 & $13 \cdot 2$ & $14 \cdot 2$ & $17 \cdot 5$ & $\geq 0.05$ \\
\hline Yogurt & $18 \cdot 1$ & $25 \cdot 6^{*}$ & $31 \cdot 8^{*}$ & $41 \cdot 1^{*}$ & $<0.001$ & $13 \cdot 8$ & $26 \cdot 5^{*}$ & $27 \cdot 4^{*}$ & $41^{*}$ & $<0.001$ \\
\hline Eggs and egg dishes & 12.9 & $9 \cdot 0^{*}$ & $11 \cdot 0$ & $11 \cdot 0$ & $\geq 0.05$ & $18 \cdot 4$ & $17 \cdot 1$ & $18 \cdot 8$ & 20.9 & $\geq 0.05$ \\
\hline Fats and spreads & $8 \cdot 6$ & 7.9 & $7 \cdot 7$ & 9.5 & $<0.01$ & $12 \cdot 2$ & $10 \cdot 4$ & $10 \cdot 0^{*}$ & $13 \cdot 4$ & $<0.001$ \\
\hline Meat & $85 \cdot 3$ & $78 \cdot 9$ & $74 \cdot 2^{\star}$ & $75 \cdot 8^{*}$ & $\geq 0.05$ & $121 \cdot 3$ & $108 \cdot 1$ & $99 \cdot 2^{*}$ & $98 \cdot 9^{*}$ & $<0.01$ \\
\hline White meat & $32 \cdot 6$ & 28 & $25 \cdot 6^{*}$ & $23 \cdot 5^{\star}$ & $<0.01$ & $37 \cdot 8$ & $36 \cdot 6$ & $33 \cdot 8$ & $33 \cdot 7$ & $\geq 0.05$ \\
\hline Red meat & $52 \cdot 7$ & 51 & $48 \cdot 6$ & $52 \cdot 2$ & $\geq 0.05$ & 83.5 & $71 \cdot 6$ & $65 \cdot 4^{*}$ & $65 \cdot 2^{*}$ & $<0.001$ \\
\hline Fish and fish dishes & $9 \cdot 3$ & $9 \cdot 8$ & $10 \cdot 4$ & 11.9 & $\geq 0.05$ & $15 \cdot 2$ & $19 \cdot 5^{*}$ & $27 \cdot 5^{\star}$ & $30 \cdot 4^{*}$ & $<0.001$ \\
\hline Fruit and vegetables & $154 \cdot 6$ & $173 \cdot 5^{\star}$ & $193 \cdot 1^{*}$ & $220 \cdot 2^{*}$ & $<0.001$ & $214 \cdot 1$ & $245^{\star}$ & $302 \cdot 3^{\star}$ & $352 \cdot 8^{*}$ & $<0.001$ \\
\hline Fruit & $63 \cdot 2$ & $79 \cdot 9^{\star}$ & $92^{*}$ & $105 \cdot 9^{\star}$ & $<0.001$ & $60 \cdot 3$ & $83 \cdot 7^{*}$ & $110 \cdot 4^{*}$ & $142^{*}$ & $<0.001$ \\
\hline Vegetables & 91.4 & $93 \cdot 6$ & $101 \cdot 1$ & $114 \cdot 3^{\star}$ & $<0.001$ & $153 \cdot 9$ & $161 \cdot 3$ & $191 \cdot 9^{\star}$ & $210 \cdot 8^{*}$ & $<0.001$ \\
\hline Pasta, rice and other cereals & $87 \cdot 5$ & $76 \cdot 8$ & $76 \cdot 8$ & $79 \cdot 1$ & $\geq 0.05$ & $74 \cdot 1$ & 72.9 & $69 \cdot 4$ & $81 \cdot 7$ & $\geq 0.05$ \\
\hline Bread (all breads) & $68 \cdot 7$ & $65 \cdot 1$ & $68 \cdot 8$ & $82 \cdot 3^{*}$ & $<0.001$ & $89 \cdot 1$ & $73 \cdot 6^{*}$ & $76^{*}$ & $99 \cdot 6^{*}$ & $<0.001$ \\
\hline White bread & $62 \cdot 3$ & $55 \cdot 1$ & $48 \cdot 2^{*}$ & $34 \cdot 2^{*}$ & $<0.001$ & 82 & $56 \cdot 5^{\star}$ & $42 \cdot 2^{*}$ & $27 \cdot 6^{\star}$ & $<0.001$ \\
\hline Wholemeal bread & 0 & $1 \cdot 1^{*}$ & $5 \cdot 1^{*}$ & $22^{*}$ & $<0.001$ & 0 & $2 \cdot 9^{\star}$ & $13 \cdot 2^{*}$ & $48 \cdot 7^{\star}$ & $<0.001$ \\
\hline RTEC & 9.5 & $18 \cdot 8^{*}$ & $26 \cdot 5^{\star}$ & $39 \cdot 9^{*}$ & $<0.001$ & $5 \cdot 32$ & $16 \cdot 7^{*}$ & $33.9^{*}$ & $46 \cdot 3^{\star}$ & $<0.001$ \\
\hline High-fibre RTEC & 0 & $7 \cdot 4^{\star}$ & $17^{\star}$ & $30 \cdot 8^{*}$ & $<0.001$ & 0.19 & $9 \cdot 2^{*}$ & $28^{*}$ & $40 \cdot 7$ & $<0.001$ \\
\hline Other RTEC & 9.5 & 11.4 & 9.5 & $9 \cdot 1$ & $\geq 0.05$ & $5 \cdot 1$ & $7 \cdot 5^{\star}$ & 5.9 & $5 \cdot 6$ & $\geq 0.05$ \\
\hline Biscuits & $11 \cdot 6$ & $14 \cdot 1$ & $17 \cdot 1^{*}$ & $17 \cdot 1^{*}$ & $<0.01$ & $8 \cdot 0$ & $11 \cdot 6^{*}$ & $13 \cdot 5^{\star}$ & $17 \cdot 1^{*}$ & $<0.001$ \\
\hline Buns, cakes, pastries and pies & $15 \cdot 5$ & $18 \cdot 1$ & $18 \cdot 9$ & $18 \cdot 6$ & $\geq 0.05$ & $14 \cdot 6$ & $17 \cdot 8$ & $21 \cdot 4^{\star}$ & $23 \cdot 3^{\star}$ & $<0.01$ \\
\hline Confectioneries & $15 \cdot 3$ & $19 \cdot 5$ & $17 \cdot 3$ & $17 \cdot 8$ & $\geq 0.05$ & $10 \cdot 8$ & $10 \cdot 2$ & 8.9 & 9.5 & $\geq 0.05$ \\
\hline Sugar confectionery & $4 \cdot 8$ & $9 \cdot 2^{*}$ & $7 \cdot 7^{\star}$ & $7 \cdot 5^{\star}$ & $<0.05$ & $1 \cdot 2$ & 2.4 & 1.4 & 1.7 & $\geq 0.05$ \\
\hline Chocolate confectionery & $10 \cdot 5$ & $10 \cdot 2$ & $9 \cdot 6$ & $10 \cdot 3$ & $\geq 0.05$ & $9 \cdot 6$ & $7 \cdot 8$ & $7 \cdot 5$ & $7 \cdot 8$ & $\geq 0.05$ \\
\hline Savoury crisps and snacks & $12 \cdot 4$ & $10 \cdot 1$ & $11 \cdot 7$ & $10 \cdot 3$ & $\geq 0.05$ & $8 \cdot 2$ & $6 \cdot 4$ & $6 \cdot 1^{*}$ & $5 \cdot 3^{*}$ & $<0.05$ \\
\hline n (unweighted) & 227 & 415 & 418 & 442 & & 277 & 431 & 426 & 437 & \\
\hline
\end{tabular}

RTEC, ready-to-eat cereals.

* Values are significantly different from non-consumers $(P<0.05 ; t$ test, adjusted for sex)

$\dagger$ Association across intakes of whole grain and other food intakes (linear regression, adjusted for sex).

compared with non-consumers. However, no other significant associations were seen in either adults or children/teenagers with other markers of health. Intakes of other foods and nutrients in whole grain consumers were closer to dietary reference values and indicative of an overall better diet.
We have shown in this population that the diets of whole grain consumers was more nutrient dense than that of nonconsumers. Intakes of a number of vitamins and minerals (e.g. Fe and magnesium and several B vitamins) were significantly increased in those consuming whole grain. This reflects

Table 4. Mean health marker outcome for non-consumers and by tertiles $(T)$ of whole grain intake

\begin{tabular}{|c|c|c|c|c|c|c|c|c|c|c|}
\hline \multirow[b]{3}{*}{ Health marker } & \multicolumn{4}{|c|}{ Child/teenage mean } & \multirow[b]{3}{*}{$\mathrm{P}$} & \multicolumn{4}{|c|}{ Adult mean } & \multirow[b]{3}{*}{$P$} \\
\hline & \multicolumn{4}{|c|}{ Whole grain intake/d } & & \multicolumn{4}{|c|}{ Whole grain intake/d } & \\
\hline & $0 \mathrm{~g} / \mathrm{d}$ & $T 1$ & $T 2$ & T3 & & $0 \mathrm{~g} / \mathrm{d}$ & $T 1$ & $T 2$ & T3 & \\
\hline Weight (kg) & $60 \cdot 1$ & 57.8 & 56 & 57.4 & 0.21 & $78 \cdot 1$ & $76 \cdot 8$ & $76 \cdot 8$ & $77 \cdot 9$ & 0.91 \\
\hline BMI & 22 & 21.9 & $21 \cdot 3$ & $21 \cdot 1$ & 0.38 & $27 \cdot 2$ & $27 \cdot 3$ & $27 \cdot 3$ & $27 \cdot 1$ & 0.94 \\
\hline$n$ (unweighted) & 120 & 155 & 146 & 147 & & 240 & 401 & 394 & 408 & \\
\hline Waist:hip ratio & 0.8 & $0 \cdot 8$ & 0.8 & $0 \cdot 8$ & 0.78 & 0.9 & 0.9 & 0.9 & 0.9 & 0.14 \\
\hline$n$ (unweighted) & 94 & 119 & 112 & 104 & & 199 & 316 & 329 & 312 & \\
\hline Systolic blood pressure (mmHg) & $110 \cdot 3$ & $109 \cdot 3$ & $107 \cdot 1^{*}$ & $107 \cdot 4^{*}$ & $0.03 \dagger$ & $125 \cdot 0$ & $126 \cdot 4$ & $127 \cdot 3$ & $127 \cdot 7$ & 0.48 \\
\hline Diastolic blood pressure $(\mathrm{mmHg})$ & $63 \cdot 3$ & $63 \cdot 3$ & $62 \cdot 6$ & $61 \cdot 6$ & 0.36 & 73.0 & $73 \cdot 3$ & $73 \cdot 3$ & 73.9 & 0.94 \\
\hline$n$ (unweighted) & 111 & 192 & 193 & 186 & & 138 & 256 & 272 & 254 & \\
\hline Cholesterol (mmol/l) & 3.9 & $4 \cdot 2$ & 4.0 & 4.0 & 0.45 & $5 \cdot 1$ & $5 \cdot 2$ & $5 \cdot 1$ & $5 \cdot 2$ & 0.57 \\
\hline $\mathrm{HDL}(\mathrm{mmol} / \mathrm{l})$ & 1.4 & 1.4 & 1.4 & 1.4 & 0.80 & 1.4 & 1.5 & 1.5 & 1.5 & 0.45 \\
\hline LDL (mmol/l) & $2 \cdot 2$ & 2.5 & $2 \cdot 3$ & $2 \cdot 3$ & 0.28 & $3 \cdot 1$ & $3 \cdot 1$ & $3 \cdot 0$ & $3 \cdot 2$ & 0.38 \\
\hline C-reactive protein (mg/l) & $3 \cdot 0$ & $2 \cdot 1$ & $2 \cdot 0$ & 1.6 & 0.29 & $3 \cdot 8$ & $2 \cdot 8^{*}$ & 2.9 & $3 \cdot 0$ & 0.23 \\
\hline TAG (mmol/l) & $0 \cdot 8$ & $0 \cdot 8$ & $0 \cdot 8$ & $0 \cdot 7$ & 0.74 & 1.5 & 1.4 & $1 \cdot 3$ & 1.3 & 0.36 \\
\hline Leucocyte count (109/l) & $7 \cdot 3$ & 5.9 & $6 \cdot 2$ & $6 \cdot 0$ & $0.04 \dagger$ & $6 \cdot 9$ & 6.5 & $6 \cdot 3^{*}$ & $5 \cdot 9^{*}$ & $0.01 \dagger$ \\
\hline $\mathrm{Hb}(\mathrm{g} / \mathrm{dl})$ & 141 & 136 & 135 & 138 & 0.22 & 143 & 140 & 141 & 142 & 0.59 \\
\hline Creatinine $(\mu \mathrm{mol} / \mathrm{l})$ & $66 \cdot 1$ & 65.9 & $62 \cdot 4$ & $16 \cdot 8$ & 0.43 & $79 \cdot 6$ & $79 \cdot 7$ & $80 \cdot 8$ & 82.9 & 0.46 \\
\hline$n$ (unweighted) & 42 & 51 & 54 & 53 & & 87 & 160 & 163 & 170 & \\
\hline
\end{tabular}

${ }^{*}$ Values are significantly different from non-consumers $(P<0.05$; $t$ test, adjusted for sex)

$\dagger P<0.05$ association across intakes of whole grain and health marker (linear regression, adjusted for sex). 
the naturally higher content of these nutrients in whole-grain foods that are lost in the manufacture of refined flours unless replaced by mandatory fortification. It is difficult to rule out confounding of overall healthy diet and lifestyle that comes hand in hand with whole grain consumption, so it is not clear whether these differences in nutrient intake are solely due to the intake of whole grain or the combined effect of consuming a healthier diet overall. However, this pattern of improved nutrient profile has also seen in similar population studies investigating the difference between whole grain consumers and non-consumers in North America and Europe ${ }^{(18-22)}$.

For many populations, including the US population, wholegrain foods make a substantial contribution to total dietary fibre intake ${ }^{(5)}$. Our findings, for this cross-section of the UK population, confirm this observation, with nutritionally significant higher fibre intakes in those that consume even a small amount of whole grain (on average $5 \mathrm{~g} / \mathrm{d}$ more in children/ teenagers and $8 \mathrm{~g} / \mathrm{d}$ more in adults). It is important to note that the higher dietary fibre intake reported here may not exclusively come from whole-grain foods, but may also come from other sources such as fruit and vegetables, intakes of which were significantly higher in both children/teenager and adult whole grain consumers compared with non-consumers (Table 3). However, the recommended intake of five portions of fruit and vegetables per $d$ was not achieved by $25 \%$ of the study population ${ }^{(10)}$. Most whole-grain cereals are a rich source of fibre; for example, whole-grain wheat contains between 9 and $17 \mathrm{~g}$ of fibre per $100 \mathrm{~g}$, more than most vegetables (generally $<6 \mathrm{~g} / 100 \mathrm{~g})^{(6)}$. This suggests that the majority of the increase in fibre intake may be attributed to the increase in whole grain intake. On the basis of the epidemiological evidence of the benefits of increased whole grain and fibre intakes, the recently revised Nordic nutrition recommendations ${ }^{(23)}$ now state that fibre intake should come from 'foods naturally rich in dietary fibre such as whole grain...' whereas whole grains had not been mentioned before. A greater emphasis on a recommendation to increase whole grain intake in the UK would potentially contribute to increasing fibre intakes in this population, as seen in a 4-month whole-grain food intervention study where a marked increase in dietary fibre intake was achieved compared with baseline ${ }^{(4)}$. Putting greater emphasis on increasing whole grain consumption will be essential if the recommendation by the UK Scientific Advisory Committee on Nutrition to increase the dietary reference value for dietary fibre for an adult population to $30 \mathrm{~g} / \mathrm{d}$ is to be achieved $^{(24)}$.

In addition to the fibre contained in whole grains, there are also fatty acids, oligosaccharides and antioxidants that have anti-inflammatory and immune stimulating properties in the human body ${ }^{(6)}$. Across tertiles of whole grain intake, we observed a significant reduction in leucocyte counts and a difference in adult CRP concentrations between non-consumers and low whole grain consumers. Leucocyte counts and CRP concentrations are markers of immune response and inflammation within the body, and are linked to the pathogenesis of CVD and $\mathrm{T}_{2} \mathrm{D}^{(25,26)}$. It is interesting that even at the reported low level of whole grain intake in this population, such associations were observed. Similar changes in CRP were seen in two cross-sectional studies where CRP concentrations were lower in whole-grain bread consumers ${ }^{(27)}$ and across whole grain intake categories ${ }^{(28)}$. In contrast to the results reported here, the associations of whole grain intake with inflammatory markers are not consistently supported by intervention studies ${ }^{(29)}$. Many of these studies have reported no change in inflammatory markers, notably CRP and IL-6 over 4-month, 12- and 6-week intervention periods ${ }^{(4,30,31)}$. The difference in observation may be due to short-term dietary intervention period, seasonality and small number of participants in the intervention groups. Further and more detailed investigation into markers of inflammation and increase in whole grain intake is required.

In common with some cross-sectional and observational studies, we were unable to see significant differences in blood pressure, BMI and blood analytes ${ }^{(21,32,33)}$, including cholesterol concentrations between consumers and non-consumers and across levels of intake ${ }^{(34)}$. This may be due to the overall low whole grain intake seen in this population, and also the relatively small sample size. Fewer than $30 \%$ of the population achieved the minimum recommended whole grain intake that may reduce the risk of CVD, T2D, overweight and obesity ${ }^{(3)}$. With the majority of population consuming such low levels of whole grain, it will be difficult to detect any improvement in health markers.

\section{Conclusion}

Whole grain intake for over $70 \%$ of this population fell below dietary recommendation in other countries for decreased risk of CVD and T2D. This low intake of whole grain may explain the small variation across markers of health in this population. After adjustment for sex and age, only significant associations of increased whole grain intake with a fall in leucocyte counts and a significant difference in CRP concentrations between the low consumers and nonconsumers (in adults only) were seen. The nutrient intakes of whole grain consumers compared with the non-consumers were closer to dietary reference values, particularly for fibre intake, suggesting that increasing whole grain intake is associated with improved diet quality. The results suggest that even small intakes of whole grain may contribute to better health and diet pattern, and that increased whole grain intake should be encouraged.

\section{Acknowledgements}

The authors thank the NatCen Social Research, MRC Human Nutrition Research and University College London Medical School for conducting and coordinating the NDNS-RP, the UK data archive for supply of the data and all the participants of the NDNS-RP.

The NDNS-RP was funded by the Department of Health and Foods Standard Agency. The present study was supported by Cereal Partners Worldwide who had no influence over the design or analysis of the present study. 
The authors' contributions are as follows: K. D. M. and C. J. S. obtained the data from the UK data archive; K. D. M. was responsible for analysing and interpreting the data; K. D. M. drafted the article; C. J. S. and M. S. P. supervised the study and contributed to the writing of the manuscript; $\mathrm{B}$. M. and F. T. critically revised the manuscript for intellectual content. All authors approved the final version of the manuscript.

K. D. M. and C. J. S. have received unrestricted research funding from Cereal Partners Worldwide. There are no other conflicts of interest to declare.

\section{References}

1. Ye EQ, Chacko SA, Chou EL, et al. (2012) Greater wholegrain intake is associated with lower risk of Type 2 diabetes, cardiovascular disease, and weight gain. $J$ Nutr 142, 1304-1313.

2. Kyrø C, Skeie G, Loft S, et al. (2013) Intake of whole grains from different cereal and food sources and incidence of colorectal cancer in the Scandinavian HELGA cohort. Cancer Causes Control 24, 1363-1374.

3. Ferruzzi MG, Jonnalagadda SS, Liu S, et al. (2014) Developing a standard definition of whole-grain foods for dietary recommendations: summary report of multidisciplinary expert roundtable discussion. Adv Nutr 5, 164-176

4. Brownlee IA, Moore C, Chatfield M, et al. (2010) Markers of cardiovascular risk are not changed by increased whole-grain intake: the WHOLEheart study, a randomised, controlled dietary intervention. Br J Nutr 104, 125-134.

5. Reicks M, Jonnalagadda S, Albertson AM, et al. (2014) Total dietary fibre intakes in the US population are related to whole grain consumption: results from the National Health and Nutrition Examination Survey 2009 to 2010. Nutr Res 34, 226-234.

6. Fardet A (2010) New hypotheses for the health-protective mechanisms of whole-grain cereals: what is beyond fibre? Nutr Res Rev 23, 65-134.

7. Mann KD, Pearce MS, McKevith B, et al. (2015) Low whole grain intake in the UK: results from the National Diet and Nutrition Survey rolling programme 2008-2011. (In the Press)

8. USDA and U.S. Department of Health and Human Services (2010) Dietary Guidelines for Americans 2010. http:// www.cnpp.usda.gov/DietaryGuidelines.htm （accessed August 2014)

9. DTU (National Food Institute) (2008) Report of the National Food Institute. http://wholegrainscouncil.org/files/WholeGrainsinDenmark.pdf (accessed August 2014).

10. Department of Health (2012) National Diet and Nutrition Survey Headline results from years 1,2 and 3 (combined) of the Rolling Programme (2008/2009-2010/11). http://web archive.nationalarchives.gov.uk/20130402145952/http://media. dh.gov.uk/network/261/files/2012/07/ndns-y3-report_alltext-docs-combined.pdf (accessed August 2014).

11. Almoosawi S, Cole D, Nicholson S, et al. (2014) Biomarkers of diabetes risk in the National Diet and Nutrition Survey rolling programme (2008-2011). J Epidemiol Community Health 68, 51-56.

12. Medical Research Council (2013) National Diet and Nutrition Survey. http://www.mrc-hnr.cam.ac.uk/research/nutritionsurveys-and-studies/national-diet-and-nutrition-survey/ (accessed August 2013).

13. Department of Health (2012) National Diet and Nutrition Survey Headline results from years 1, 2 and 3 (combined) of the Rolling Programme, Appendix A: dietary data collection and editing (2008/2009-2010/11). http://webarchive.natio nalarchives.gov.uk/20130402145952/http://media.dh.gov.uk/ network/261/files/2012/07/appendix-a-dietary-data-collectionand-editing.pdf (accessed August 2014)

14. Hirani V \& Mindell J (2008) A comparison of measured height and demispan equivalent height in the assessment of body mass index among people aged 65 years and over in England. Age Ageing 37, 311-317.

15. Van Der Kamp JW, Poutanen K, Seal CJ, et al. (2014) The HEALTHGRAIN definition of 'whole grain'. Food Nutr Res 58, 22100 .

16. Seal CJ, Jones AR \& Whitney AD (2006) Whole grains uncovered. Nutr Bull 31, 129-137.

17. Department of Health (2012) National Diet and Nutrition Survey Headline results from years 1,2 and 3 (combined) of the Rolling Programme, Appendix B: weighting the NDNS core sample (2008/2009-2010/11). http://webarchive.natio nalarchives.gov.uk/20130402145952/http://media.dh.gov.uk/ network/261/files/2012/07/appendix-b-weighting-the-ndnscore-sample.pdf (accessed August 2014).

18. O'Neil CE, Nicklas TA, Zanovec M, et al. (2010) Consumption of whole grains is associated with improved diet quality and nutrient intake in children and adolescents: the National Health and Nutrition Examination Survey 1999-2004. Public Health Nutr 14, 347-355.

19. O'Neil CE, Nicklas TA, Zanovec M, et al. (2010) Whole grain consumption is associated with diet quality and nutrient intake in adults: the National Health and Nutrition Examination Survey 1999-2004. J Am Diet Assoc 110, 1461-1468.

20. Devlin NFC, NcNulty BA, Gibney MJ, et al. (2013) Whole grain intakes in the diets of Irish children and teenagers. Br J Nutr 110, 345-362.

21. Bellisle F, Hébel P, Colin J, et al. (2014) Consumption of whole grains in French children, adolescents and adults. Br J Nutr 112, 1674-1684.

22. Kyrø C, Skeie G, Dragsted LO, et al. (2011) Intake of whole grains in Scandinavia is associated with healthy lifestyle, socio-economic and dietary factors. Public Health Nutr $\mathbf{1 4}$ 1787-1795.

23. Norden (2012) Nordic Nutrition Recommendations 2012 http://www.norden.org/en/news-and-events/news/newnordic-nutrition-recommendations-e-book-e-chapters-nowonline (accessed August 2014).

24. Scientific Advisory Committee on Nutrition (2014) Draft Carbohydrates and Health Report. https://www.gov.uk/ government/uploads/system/uploads/attachment_data/file/ 339771/Draft_SACN_Carbohydrates_and_Health_report_ consultation.pdf (accessed June 2014).

25. Donath MY \& Shoelson SE (2011) Type 2 diabetes as an inflammatory disease. Nat Rev Immunol 11, 98-107.

26. Masters RC, Liese AD, Haffner SM, et al. (2010) Whole and refined grain intakes are related to inflammatory protein concentrations in human plasma. J Nutr 140, 587-594.

27. Montonen J, Boeing H, Fritsche A, et al. (2013) Consumption of red meat and whole-grain bread in relation to biomarkers of obesity, inflammation, glucose metabolism and oxidative stress. Eur J Nutr 52, 337-345.

28. Lutsey PL, Jacobs DR Jr, Kori S, et al. (2007) Whole grain intake and its cross-sectional association with obesity, insulin resistance, inflammation, diabetes and subclinical CVD: the MESA study. Br J Nutr 98, 397-405.

29. Buyken AE, Goletzke J, Joslowski G, et al. (2014) Association between carbohydrate quality and inflammatory markers: systematic review of observational and interventional studies. Am J Clin Nutr 99, 813-833. 
30. Tighe P, Duthie G, Vaughan N, et al. (2010) Effect of increased consumption of whole-grain foods on blood pressure and other cardiovascular risk markers in healthy middle-aged persons: a randomized controlled trial. $\mathrm{Am} \mathrm{J}$ Clin Nutr 92, 733-740.

31. Anderson A, Tengblad S, Karlstrom B, et al. (2007) Wholegrain foods do not affect insulin sensitivity or markers of lipid peroxidation and inflammation in healthy, moderately overweight subjects. J Nutr 137, 1401-1407.

32. Cheng G, Karaolis-Danckert N, Libuda L, et al. (2009) Relation of dietary glycemic load, and fibre and whole-grain intakes during puberty to the concurrent development of percent body fat and body mass index. Am J Epidemiol 169, 667-677.

33. Zanovec MS, O'Neil CE, Cho SS, et al. (2010) Relationship between whole grain and fibre consumption and body weight measures among 6- to 18-year-olds. I Pediatr 157, $578-583$.

34. Jensen MK, Koh-Banerjee P, Franz M, et al. (2006) Whole grains, bran and germ in relation to homocysteine and markers of glycemic control, lipids and inflammation. Am J Clin Nutr 83, 275-283. 